\title{
Sea Surface Height changes in the North Atlantic Ocean related to the North Atlantic Oscillation
}

\author{
Saskia Esselborn ${ }^{1}$ \\ Institut für Meereskunde, Universität Hamburg, Germany \\ Carsten Eden \\ Dalhousie University, Halifax, Canada.
}

\begin{abstract}
Interannual sea surface height (SSH) variability as measured by the Topex/Poseidon satellite altimeters is investigated for the North Atlantic Ocean between 1992 and 1998. The SSH variability exhibits a basin-wide coherent dipole structure between the subtropical and the subpolar North Atlantic. The SSH dipole pattern changed sign between 1995 and 1996, coinciding with a change of sign of the North Atlantic Oscillation (NAO). The large-scale SSH pattern is reproduced with an ocean general circulation model, and can be traced back to changes in the atmospheric forcing related to the NAO. The model reveals that the interannual SSH anomalies are mainly caused by changes in the oceanic heat transport which are connected with the response of the large-scale ocean circulation to changes in the wind stress curl. Variations in the local heat flux reinforce these SSH anomalies but are of minor importance.
\end{abstract}

\section{Introduction}

In the North Atlantic, interannual atmospheric variability is dominated by the simultaneous weakening of the Icelandic Low and strenghtening of the Azores High, the so-called North Atlantic Oscillation (NAO) [Walker, 1924; Hurrel, 1995]. In order to study the accompanying ocean heat content variability we are focussing on the relationship between the NAO and basin-wide, interannual Sea Surface Height (SSH) changes between $15^{\circ} N-65^{\circ} N$, assuming that SSH and heat content changes are strongly correlated [Chambers et al., 1997]. Large-scale, long-term persistent SSH anomalies may point toward a possible oceanic forcing of the atmosphere on interannual time scales which may lead to enhanced predictability of the atmosphere on such time scales. SSH has been measured with high temporal and spatial resolution by satellite altimeters with an accuracy of 2-3 $\mathrm{cm}$ since the beginning of the 1990s [Cheney et al., 1994]. In addition to the observations, we use a non-eddy-resolving general circulation model of the Atlantic Ocean to investigate the SSH response to idealized surface forcing related to high NAO-phases. This SSH response could either be induced by local buoyancy forcing or by dynamical adjustment of the ocean circulation to the altered forcing. The dynamical response of the ocean circulation to changes in

\footnotetext{
${ }^{1}$ Now at IfK, GKSS, Geesthacht, Germany.
}

Copyright 2001 by the American Geophysical Union.

Paper number 2001GL012863.

0094-8276/01/2001GL012863\$05.00 the phase of the NAO was already discussed by Eden and Willebrand [2001].

\section{Altimeter Data}

The SSH data has been measured every ten days since October 1992 by the joint US/French satellite altimeter Topex/Poseidon (T/P) on repeat-tracks with a maximum track separation of $2.8^{\circ}$ in longitude. The first 6 years of the T/P SSH data were provided by the Space Oceanography Division of Collecte Localisation Satellites (CLS) in Toulouse, France [AVISO, 1997]. The processing of the data by CLS involves the correction of the usual instrumental, media, and geophysical effects including tides and atmospheric loading.

For every season in the period from winter 1992/93 to summer 1998 we have calculated SSH anomalies which were referenced to the mean seasonal SSH along the satellite tracks. The seasons were averaged for December to February, March to May, June to July, and September to November. Finally, the SSH anomalies were spatially interpolated to a $1^{\circ}$ by $1^{\circ}$ grid using Gaussian weighting functions. The accuracy of the monthly gridded SSH measured by $T / P$ is estimated to be 2-3 cm [Cheney et al., 1994], and should be better than $1 \mathrm{~cm}$ for the investigated temporal means, provided that errors are uncorrelated between the individual cycles.

\section{Numerical Model}

The general circulation model is an improved version of the GFDL MOM2.1 code [Pacanowski, 1995], which was developed as part of FLAME (http://www.ifm.unikiel.de/to/FLAME). The model domain is the entire Atlantic Ocean and the resolution is $4 / 3^{\circ}$ in longitude and

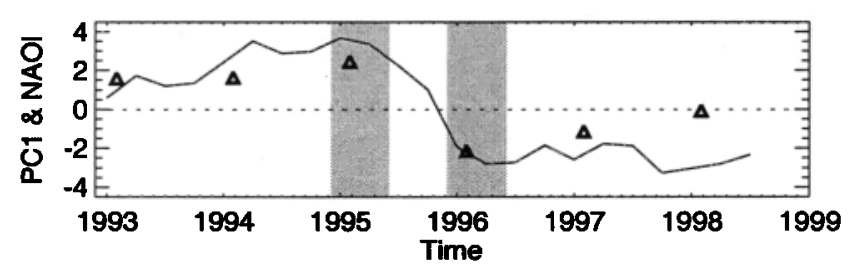

Figure 1. 1st Principal Component of the seasonal SSH anomalies $(-)$ measured by $T / P$ and winter NAO-index $(\triangle)$ calculated from normalized sea level pressure difference between Azores and Iceland after Hurrel [1995]. Periods used for the calculation of NAO high-low composites are underlaid in gray. 

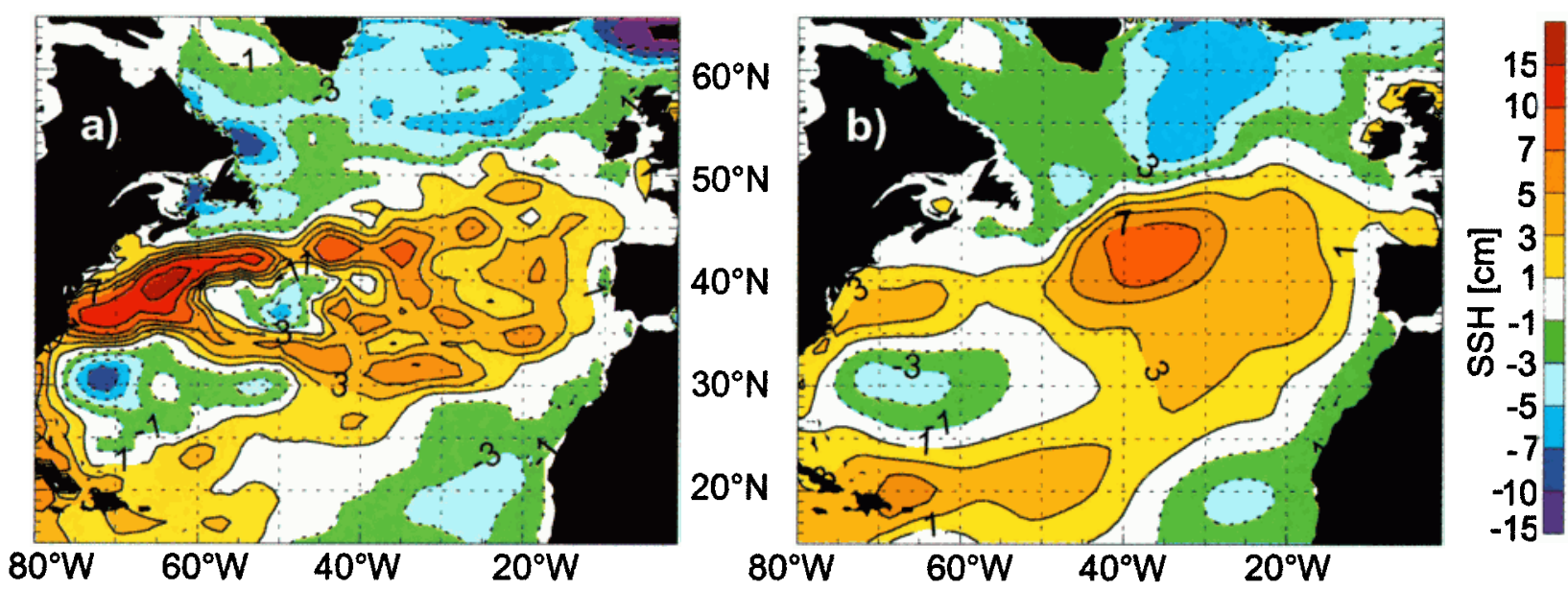

Figure 2. SSH composite for December 1994 to May 1995 minus December 1995 to May 1996, a) from T/P data and b) from experiment EXP-NCEP in $\mathrm{cm}$.

$4 / 3^{\circ} \cos \phi$ in latitude. The model is forced during a 50 -year spinup phase with monthly climatological fluxes taken from Barnier et al. [1995]. For the following experiments surface flux anomalies derived from the NCEP/NCAR reanalysis data [Kalnay et al., 1996] were added to the climatological fluxes to force the model. More details concerning the model and the configuration are given by Eden and Jung [2001] and Eden and Willebrand [2001]. Note that a set of experiments similar to the one discussed here is also used in Eden and Willebrand [2001].

\section{Results}

The first Empirical Orthogonal Function (EOF) of the observed seasonal SSH anomalies explains $34 \%$ of the variance. It reveals a basin scale dipol in the subtropical and the subpolar North Atlantic in good agreement with the results of Reverdin et al. [1999]. The corresponding principal component $(\mathrm{PC})$ is shown in Figure 1 together with the winter NAO-index. The most prominent signal in the leading PC

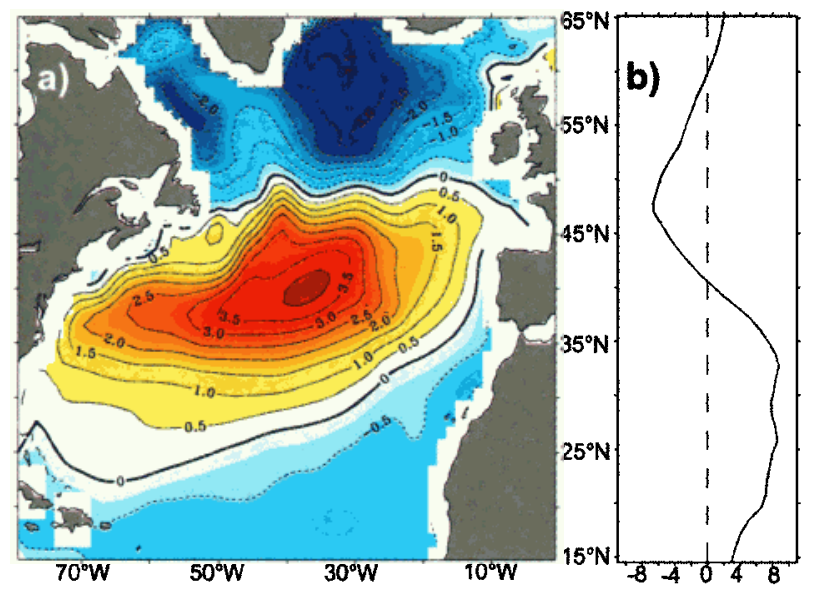

Figure 3. a) SSH anomaly for the first year of experiment EXP-NAO (relative to the last year of the spinup phase) in $\mathrm{cm}$ (0.5 intervals). b) Meridional heat transport change in the first year of EXP-NAO in $10^{-2} \mathrm{PW}$. is its change between 1995 and 1996 which coincides with a pronounced drop in the NAO-index. This suggests that the basin-wide changes in the observed SSH may be related to the NAO. However, the relation remains quite speculative at this point due to the restricted length of the observed time-series.

To highlight the spatial characteristics of the SSH changes accompanying the shift in the NAO we have calculated the difference in SSH for the two periods marked in Figure 1. The SSH difference for December 1994 to May $1995 \mathrm{mi}-$ nus December 1995 to May 1996, representing a high-low NAO composite, is shown in Figure 2a). For this composite the SSH is increased by $3-8 \mathrm{~cm}$ in midlatitudes and decreased by $2-7 \mathrm{~cm}$ in the subpolar gyre. A very similar large scale pattern of SSH variability is also revealed by the leading EOF of the SSH as well as by a composite analysis of the seasonal SSH changes and the NAO index for 1993-1998 (not shown). The basin-scale SSH, which is corrected for tidal and atmospheric loading effects, is dominated by temperature-induced expansion and contraction of the oceanic upper layer with only minor contributions by changes in salinity and bottom pressure [Gill and Niiler, 1973]. Therefore, we can derive changes of oceanic heat content from the changes in SSH [Chambers et al., 1997]. Using climatological thermal expansion coefficients for the upper layer we have estimated a mean heat loss of $1.1 \mathrm{GJ} / \mathrm{m}^{2}$ in the subpolar region between $50^{\circ} \mathrm{N}-65^{\circ} \mathrm{N}$ and a heat gain of $0.4 \mathrm{GJ} / \mathrm{m}^{2}$ in midlatitudes between $30^{\circ} \mathrm{N}-45^{\circ} \mathrm{N}$ for the high-low NAO composite.

For further investigation we have performed experiments with the numerical model. In order to check the performance of the model it was forced with surface fluxes for the period 1958-1997 in experiment EXP-NCEP. There is a fair agreement between model results and observations for the basin-scale SSH changes. An example is given in Figure $2 \mathrm{~b}$ ) which shows the difference for December 1994 to May 1995 minus December 1995 to May 1996 for the diagnosed SSH in EXP-NCEP. The structure as well as the amplitude of the simulated SSH pattern is very similar to the observations. The corresponding heat content change in the model is an mean heat loss of $1.0 \mathrm{GJ} / \mathrm{m}^{2}$ in the subpolar region and a heat gain of about $0.6 \mathrm{GJ} / \mathrm{m}^{2}$ in midlatitudes, which agrees 
a)

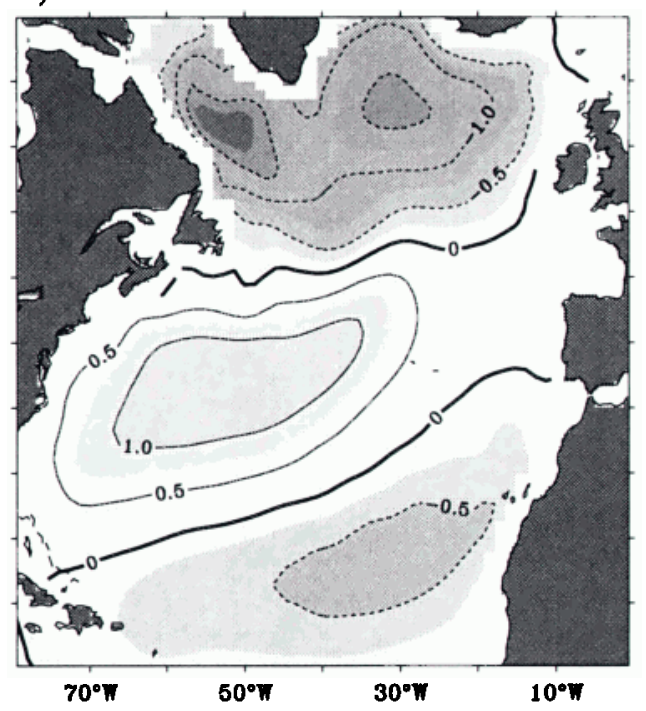

b)

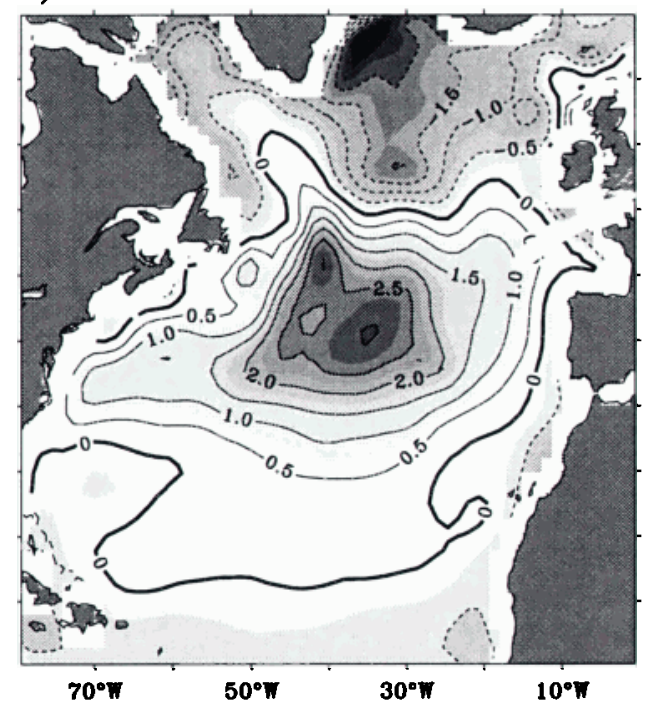

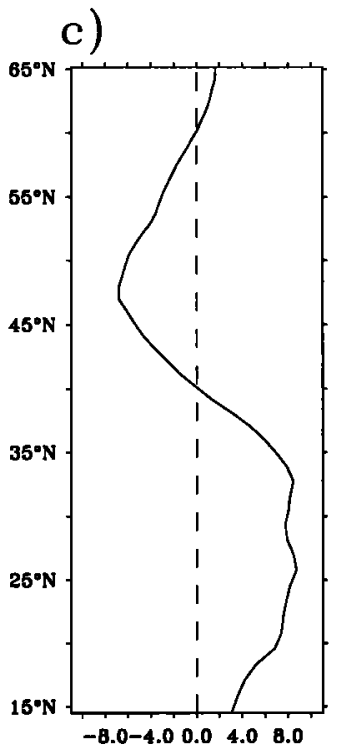

Figure 4. SSH anomaly for the first year of experiment a) EXP-NAO-HEAT and b) EXP-NAO-WIND in $\mathrm{cm}$. c) Meridional heat transport change in the first year of EXP-NAO-WIND in $10^{-2} P W$.

also quite well with the observational estimates. There are some locations where the model results deviate from the observations pointing towards deficiencies of the model. For example, the differences in the Gulf Stream area may be attributable to the fact that the model is not eddy-resolving and that the modelled Gulf Stream is hence unrealistic broad and sluggish. However, this should not influence the main conclusions drawn from the model results.

To further check whether the SSH changes between 1995 and 1996 are related to the NAO in the model and to understand the mechanisms driving these rapid SSH changes, we performed idealized response experiments to a persistent high NAO-phase. Idealized forcing patterns of the surface fluxes were constructed by regressing time-series (19581997) of wind stress and heat flux anomalies taken from NCEP data onto the NAO-index for each month of the year and adding the regressed values to the monthly climatological values. Similar to the experiments by Eden and Willebrand [2001] in experiment EXP-NAO the spun-up model was driven for one year (starting in January) with surface fluxes representative of a change in the NAO-index of 3 . The changes in SSH for EXP-NAO are shown in Figure 3a). The results of EXP-NAO are indeed in good agreement with the SSH composites derived from the observations and EXPNCEP; there is a decrease of 3-4 cm in SSH in the subpolar North Atlantic in the first year of experiment EXP-NAO and an increase with similar amplitude in midlatitudes. The corresponding heat content change is a heat loss of about 0.5 $G J / m^{2}$ in the subpolar region and a heat gain of about 0.3 $G J / m^{2}$ in midlatitudes.

The SSH and consequently heat content anomalies can be induced by local fluctuations of air-sea heat flux or by changes in lateral heat advection. Heat advection can in turn be modified by advection of heat anomalies generated by local air-sea heat flux changes or by changes in the circulation. On intraseasonal to interannual time scales, basin scale circulation changes should be induced by wind stress changes, while heat flux forcing should play a minor role on that time scale in driving circulation changes. To explore the relative importance of the heat flux and wind stress forcing for the induced SSH changes in the model, two additional experiments were performed. In experiment EXP-NAO-HEAT the model was driven solely by heat flux patterns related to a high NAO-phase (taken from the regression with the NAOindex) while the wind stress remained climatologically as in the spinup phase. In experiment EXP-NAO-WIND the model was driven by NAO related wind stress patterns while the heat flux patterns remained unchanged.

The SSH changes in experiment EXP-NAO-HEAT are shown in Figure 4a). The SSH pattern resembles the pattern of the heat flux anomalies due to a high NAO-phase (not shown, compare e.g. [Cayan, 1992]). Note, that there is no indication of SSH changes induced by advection of locally generated heat content anomalies. Even though the resulting SSH pattern is similar to the one from EXP-NAO, amplitudes in EXP-NAO-HEAT are considerably lower than those in EXP-NAO.

The SSH changes from experiment EXP-NAO-WIND are shown in Figure $4 \mathrm{~b}$ ). There is a positive SSH anomaly centered at about $45^{\circ} \mathrm{N}, 45^{\circ} \mathrm{W}$ and a negative $\mathrm{SSH}$ anomaly centered in the Irminger Sea. The SSH changes in EXPNAO-WIND are similar to EXP-NAO suggesting that most of the interannual changes in SSH are triggered by changes in wind stress. The corresponding meridional heat transport changes for those experiments are shown in Figures 3b) and 4c). The convergences and divergences of the anomalous meridional heat transport are clearly located at the same latitudes as positive and negative SSH anomalies and are caused by changes in wind stress. This suggests that on interannual time scales in the North Atlantic north of $20^{\circ} \mathrm{N}$, changes in the oceanic heat content are primarily induced by anomalous meridional heat transports and only secondarily by changes of the local air-sea heat flux.

A more detailed discussion of the heat transport changes in similar model runs as investigated here by [Eden and Willebrand, 2001] reveals that in the subtropical gyre the anomalous heat transports are related to changes in the Ekman transport. In contrast, however, near the subpo- 
lar front and north of it, the contribution of a Sverdup-like response to the NAO-related changes in the wind stress curl and the related horizontal circulation changes dominate the heat transport anomalies.

\section{Concluding discussion}

SSH as measured by satellite altimetry increased by several centimeters in the subpolar gyre for the winter $1995 / 1996$, corresponding to a heat gain of about $1.0 \mathrm{GJ} / \mathrm{m}^{2}$ on average. The relevant aspects of this variability are well reproduced by a coarse resolution model. Recent hydrographic observations from the subpolar region show a similar gain of heat during this period. In addition, there are indications for the contribution of anomalous oceanic heat transport to the oceanic heat gain. Reverdin et al. [1999] have reported changes in upper ocean heat content between Iceland and Newfoundland in the winter 1995/1996 which correspond to an increase in steric height by about $4 \mathrm{~cm}$. Since only half of these changes can be explained by local air-sea heat fluxes they conclude that anomalous advection of heat must be an important contribution. Between Ireland and southern Greenland the heat content of the upper layer has increased between 1995 and 1996 by $3.5 \mathrm{GJ} / \mathrm{m}^{2}$ [Bersch et al., 1999]. Note, that along this section the model shows enhanced heat gain with amplitudes close to the observed value. Since the salinity was increased as well they assume that advective processes might in part be responsible for the observed changes.

There is a close correspondence between the observed patterns of interannual SSH variability and the patterns derived as the fast reaction from the idealized NAO response experiments. This confirms our hypothesis that the observed changes in SSH in winter 1995/96 are the reaction to the simultaneous drop in the NAO-index. However, in a statistical point of view this conclusion must remain speculative with respect to the restricted length of the observed SSH-time series. The fast response in the modeled SSH is primarily induced by NAO related changes in wind stress curl, which generate oceanic circulation anomalies and finally cause anomalous heat transport convergences and divergences. Thus, we conclude here under the above mentioned premise, that wind induced circulation changes represent the major factor for basin scale, interannual heat content changes in the North Atlantic.

Acknowledgments. This work was supported by German BMBF (03F0157A, WOCE IV), by NOAA as part of ACCE, and by German DFG as part of the SFB 460 "Dynamics of
Thermohaline Circulation Variability". T/P SLA products were supplied by the CLS Space Oceanography Division, Toulouse, France.

\section{References}

AVISO, AVISO User handbook for sea level anomalies (SLAs), AVI-NT-011-312-CN, Edition 3.0, 24 pp., CLS Space Oceanography Division, Toulouse, France, 1997.

Barnier,B., L. Siefridt, and P. Marchesiello, Thermal forcing for a global ocean circulation model using a three-year climatology of ECMWF analyses, J. Mar. Systems, 6, 363-380, 1995.

Bersch, M., J. Meincke, and A. Sy, Interannual thermohaline changes in the northern North Atlantic 1991-1996, Deep-Sea Res. Part II, 46, 55-75, 1999.

Cayan, D. R., Latent and sensible heat flux anomalies over the northern oceans: The connection to monthly atmospheric circulation, J. Climate, 5, 354-369, 1992.

Cox, M. D., Isopycnal diffusion in a z-coordinate ocean model, Ocean Modelling, 74, 1-5, 1987.

Chambers, D. P., B. D. Tapley, and R. H. Stewart, Long-period ocean heat storage rates and basin-scale heat fluxes from TOPEX, J. Geophys. Res., 102, 10525-10533, 1997.

Cheney, R., L. Miller, R. Agreen, N. Doyle, and J. Lillibridge, TOPEX/POSEIDON: the 2-cm solution, J. Geophys. Res., 99, 24555-24563, 1994.

Eden, C., and T. Jung, North Atlantic interdecadal variability: oceanic response to the North Atlantic Oscillation (18651997), J. Climate, 14, (5), 676-691, 2001.

Eden, C., and J. Willebrand, Mechanism of interannual to decadal variability in the North Atlantic Ocean, J. Climate, 14, (10), 2266-2280, 2001.

Gent, P. R., and J. C. McWilliams, Isopycnal mixing in ocean circulation models, J. Phys. Oceanogr., 20, 150-155, 1990.

Gill, A. E., and P. Niiler, The theory of the seasonal variability in the ocean, Deep Sea Res., 20, 141-177, 1973.

Hurrell, J. W., Decadal trends in the North Atlantic Oscillation: regional temperatures and precipitation, Science, 269, 676-679, 1995.

Kalnay, E., et al., The NCEP/NCAR 40-year reanalysis project, Bull. Amer. Meteor. Soc., 77, 437-471, 1996.

Pacanowski, R. C., MOM 2 documentation, user's guide and reference manual, GFDL Ocean Group, GFDL, Princeton, USA, 1995.

Reverdin, G., N. Verbrugge, and H. Valdimarson, Upper ocean variability betwen Iceland and Newfoundland 1993-1998, J. Geophys. Res., 104, 29599-25611, 1999.

Walker, G. T., Correlation in seasonal variation of weather, IX, Mem. Indian. Meteor. Dep., 24, 275-332, 1924.

S. Esselborn, GKSS-Research Centre, Max-Planck-Str., 21502 Geesthacht, Germany. (e-mail: saskia@gkss.de)

(Received January 11, 2001; revised May 8, 2001; accepted June 27, 2001.) 